would guarantee a certain level of support for the "science base" of NIH's activities, leaving research issues more related to health care to be discussed within the broader framework of HEW priorities.

Dr Fredrickson has indicated that he personally favours such a "mixed economy" approach to research planning. "I do not believe in the rational plan- ning of science beyond a very limited range", he told the meeting. But just how limited that range is-or should be-is likely to be the subject of heated debate in the months ahead.

\title{
Canada announces major research boost
}

The Canadran Government has announced a package of measures designed to stimulate research and development activities, the low level of support for which has recently been the target of widespread public criticism. The Government's declared intention is to raise the proportion of the nation's gross national product spent on $\mathrm{R} \& \mathrm{D}$ from $0.9 \%$ to $1.4 \%$ over the next five years.

Included in the package is an increase of $\$ 5.35$ million in the budget of the National Research Council to enable it to expand its programmes and establish university-based research centres. This should improve cooperation between Government, research and industry.

The plan also allows for an immediate increase of $\$ 10 \mathrm{~m}$ in the budgets of the three main grant-giving bodies over and above the budgets already announced for 1978-79. As a result, the budget of the newly-formed Natural Sciences and Engineering Council will increase by $12.4 \%$ to $\$ 109.8 \mathrm{~m}$ (rather than increasing by only $7.1 \%$, as originally planned). Similarly the budget of the Medical Research Council will increase by $11.1 \%$ (rather than $5.8 \%$ ), to $\$ 63 \mathrm{~m}$, and that of the Social Science and Humanities Research Council will increase by $15 \%$ (rather than $7.8 \%$ ) to $\$ 33.1 \mathrm{~m}$.

In April, the Medical Research Council announced that, with only a $5.8 \%$ increase in funds budgeted for next year, it was having to terminate a fifth of its established research projects, and would only be able to fund $30 \%$ of the grant applications which it had received and had judged worthy of support. The new money, whose distribution will be at the discretion of the council, means that such drastic cuts are no longer necessary.

Following a meeting of the council at the end of last week, a spokesman said that the increase would allow the council to continue to fund projects of national importance without having to cut into its research base.

In slight contrast to the MRC, both of the other research councils have been told that the extra money should be spent on research projects which are seen to be of national importance. This reflects the main goal of the Government's package, which is to increase the technological strength of Canadian industry.

Thus, in addition to the extra money given to the grant-issuing bodies, $\mathrm{Mr}$ Buchanan also announced that the Government would increase its contracting-out research programme in each of the next two years, and would spend $\$ 6.8 \mathrm{~m}$ to establish research centres to assist in the development of industrial research activities.

Furthermore the Government is planning to introduce a $\$ 3 \mathrm{~m}$ works programme to create jobs for scientists and technicians to undertake research projects at the request of industrial firms.

The long-term need for a major basic research effort to support a national technological development programme was also emphasised last week by Dr Josef Kates, chairman of the Science Council of Canada. In a statement published with the council's annual report, Dr Kates says that Canada's previous emphasis on technology transfer has not allowed it to participate effectively in R \& D efforts leading to successful innovations and developments.

Stressing the Science Council's demand for a policy of "technological sovereignty" as a strategy for achieving scientific, industrial and economic strength, Dr Kates said that part of this policy should include an ability to barter competently and toughly for technologies which could be used to enhance Canada's industrial base.

"Unfortunately, many of the scientific agreements negotiated between Canada and other countries seem to reflect a sense of diplomatic exchange rather than of genuine technology transfer", Dr Kates says.

Other members of the scientific community, however, while welcoming the Government's decision to increase funds for R \& D, are concerned at the apparent emphasis on targeted research. They feel that, in the longterm, support for basic research is necessary to guarantee the success of targeted research.

"We are worried that the result of this emphasis may be to leave many university scientists out in the cold. Furthermore, if industry fails to make good use of the incentives it is being offered by the Government, this could ultimately damage support for research in other sectors", Dr John Kucharcyzk, of the Canadian Federation of Biological Sciences, said last week.

David Dickson

\section{Computer secrecy ban lifted}

Following widespread criticism of apparent attempts to infringe academic freedom, the US Department of Commerce announced last week that it had decided to lift a secrecy ban imposed on 21 April on a research scientist at the University of Wisconsin-Milwaukee who has been working on the security of computer-based data systems.

According to a Department spokesman, the ban-which was imposed when the research scientist, Dr George Davida, had applied for a patent for techniques arising from his unclassified research-had originally been re- quested by the Department of Defense. It was withdrawn following an inquiry by Commerce Department officials. $\square$

\section{Fall in graduate enrolment}

The Number of graduate students enrolled in science programmes in US educational institutions fell by $1 \%$ in 1977, following continual growth since 1973, according to figures released last week by the National Science Foundation.

A $2 \%$ increase in part-time enrolment to 113,700 was more than offset by a $2 \%$ decrease in full-time numbers to 228,600 , leading to a total decrease of 3,400 between the fall of 1976 and the fall of 1977-from 345,700 and 342,300 .

Improved job opportunities for those without a PhD was one of the main reasons for the decrease, according to the NSF.

Other possible causes included a $35 \%$ reduction in the enrolment of war veterans because GI Bill benefits have expired, increasing tuition and living costs, and declining federal support to students in graduate science and engineering programmes. 